\title{
Structural Diversity of Hydrogen-Bonded 4-Aryl-3,5-Dimethylpyrazoles for Supramolecular Materials
}

\author{
Sandra Moyano ${ }^{1}$, Beatriz Diosdado ${ }^{2}$, Leire San Felices ${ }^{3}$, Anabel Elduque ${ }^{2, *}$ and Raquel Giménez ${ }^{1, *}$ \\ 1 Instituto de Nanociencia y Materiales de Aragón (INMA), Departamento de Química Orgánica, \\ Facultad de Ciencias, CSIC-Universidad de Zaragoza, 50009 Zaragoza, Spain; \\ sandra.moyano.perez@gmail.com \\ 2 Departamento de Química Inorgánica, Facultad de Ciencias, \\ Instituto de Síntesis Química y Catálisis Homogénea (ISQCH), CSIC-Universidad de Zaragoza, \\ 50009 Zaragoza, Spain; beadiosdado@hotmail.com \\ 3 Servicios Generales de Investigación SGIker, Universidad del País Vasco UPV /EHU, P.O. Box 644, \\ 48080 Bilbao, Spain; leire.sanfelices@ehu.eus \\ * Correspondence: anaelduq@unizar.es (A.E.); rgimenez@unizar.es (R.G.)
}

Citation: Moyano, S.; Diosdado, B.;

San Felices, L.; Elduque, A.; Giménez,

R. Structural Diversity of

Hydrogen-Bonded

4-Aryl-3,5-Dimethylpyrazoles for Supramolecular Materials. Materials 2021, 14, 4550. https://doi.org/ $10.3390 /$ ma14164550

Academic Editor: Lucia Carlucci

Received: 21 June 2021

Accepted: 10 August 2021

Published: 13 August 2021

Publisher's Note: MDPI stays neutral with regard to jurisdictional claims in published maps and institutional affiliations.

Copyright: (c) 2021 by the authors. Licensee MDPI, Basel, Switzerland. This article is an open access article distributed under the terms and conditions of the Creative Commons Attribution (CC BY) license (https:// creativecommons.org/licenses/by/ $4.0 /)$.

\begin{abstract}
The $1 H$-pyrazoles have high versatility and ability to form hydrogen-bonded supramolecular materials. In this study, the thermal stability, fluorescence, and H-bonding ability of the studied 3,5-dimethyl-4-(4-X-phenyl)-1H-pyrazoles showed large differences depending on the terminal substituent. Supramolecular structures were analyzed using X-ray diffraction and Hirshfeld surface calculations. Compounds were found to arrange in different hydrogen-bonded structures, depending on the substitution at the para position of the phenyl ring $\left(\mathrm{X}=\mathrm{OCH}_{3}, \mathrm{NO}_{2}, \mathrm{NH}_{2}\right)$. The methoxy-substituted compounds arranged in dimers through methanol bridges, the nitro-substituted compound formed supramolecular polymers or catemers, and the amino-substituted compound gave rise to a new structure based on a 2D hydrogen-bonded network.
\end{abstract}

Keywords: supramolecular chemistry; hydrogen bond; pyrazole; luminescence; X-ray; Hirshfeld surface analysis

\section{Introduction}

Hydrogen-bonded supramolecular materials are being investigated in diverse research areas such as for drug development [1], energetic materials [2], porous supramolecular organic frameworks [3], or functional soft materials [4,5]. By making use of engineered supramolecular interactions, such as directional hydrogen bonds, small predesigned molecular units can generate structural complexity and improve functions in organic materials, avoiding the use of complex covalent synthetic routes.

The particular structure of $1 \mathrm{H}$-pyrazole makes this cycle a versatile supramolecular synthon for crystal engineering [6,7]. The different characteristics of the two adjacent nitrogens in the five-member cycle of $1 \mathrm{H}$-pyrazole, namely the pyrrol-type nitrogen $(\mathrm{N} 1-\mathrm{H})$ and the pyridine-type nitrogen (N2), allow hydrogen-bonded interactions to be established with different topologies (monodentate, exobidentate) [8,9], as well as multiple bridge modes to be established between pyrazole cycles such as dimers, trimers, tetramers, or polymeric structures (catemers) $[10,11]$. Such structural diversity and the dynamic character of the hydrogen bonds mean pyrazole derivatives have great potential for the development of functional materials.

Substitution of the $1 H$-pyrazole cycle at the 4 position with a phenyl ring increases the anisotropy and endows the structure with fluorescent properties. In particular, the 3,5-dimethyl-4-arylpyrazole platform has been incorporated in different structures, yielding functional soft materials such as liquid crystals [12,13] or responsive supergels [14], in which hydrogen bonding plays an important role in their organization and properties. Also 
of interest is the ability to maintain fluorescence in the solid or aggregated state and show aggregation-induced emission (AIE) [12,14]; that is, the luminescence is not quenched but enhanced at high concentrations or in the bulk $[15,16]$, contrary to the behavior of standard organic fluorophores.

In order to shed light on the structure and hydrogen bonding modes of anisotropic 3,5-dimethyl-4-arylpyrazoles that would help to develop predictable supramolecular organizations, selected model structures with nitrogen- or oxygen-derived substituents at the para position of the phenyl ring were studied here in the solid state. Three compounds derived from 3,5-dimethyl-4-(4-X-phenyl)- $1 H$-pyrazoles-namely X methoxy, nitro, and amino groups (Scheme 1) -were synthesized, their thermal and optical properties were studied, and their supramolecular structures were analysed using $X$-ray diffraction and Hirshfeld surface calculations.

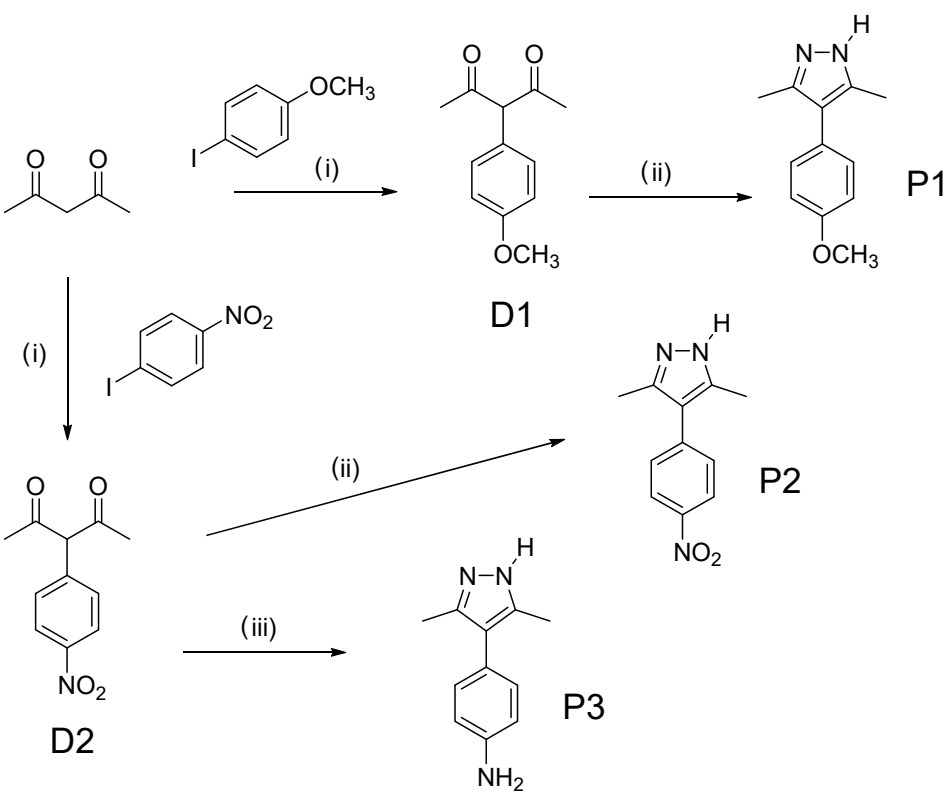

Scheme 1. Synthetic routes for the preparation of the final pyrazole compounds: (i) (1) CuI, L-proline, $\mathrm{K}_{2} \mathrm{CO}_{3}$, DMSO; (2) $\mathrm{HCl} 1 \mathrm{M}$; (ii) $\mathrm{N}_{2} \mathrm{H}_{4} \cdot \mathrm{H}_{2} \mathrm{O}, \mathrm{EtOH}$; (iii) $\mathrm{N}_{2} \mathrm{H}_{4} \cdot \mathrm{H}_{2} \mathrm{O}$, graphite, EtOH.

\section{Materials and Methods}

\subsection{Techniques}

All starting materials and solvents were obtained from commercial sources and used without purification. Nuclear magnetic resonance (NMR) spectra were measured on a Bruker Avance 400 spectrometer. Chemical shifts are given in ppm relative to tetramethylsilane (TMS) and the solvent residual peak was used as the internal standard. Microanalyses were performed with a Perkin-Elmer 2400 microanalyzer. Infrared (IR) spectra were recorded on a Nicolet Avatar FTIR spectrophotometer using KBr pellets. Mass spectra (MS) were obtained on a MICROFLEX Bruker spectrometer. Optical microscopy was studied using an Olympus BX51 microscope equipped with a Linkam THMS600 hot stage. Thermogravimetric analysis (TGA) was performed using a TA Instruments Q5000 apparatus at a heating rate of $10{ }^{\circ} \mathrm{C} \mathrm{min}-1$ under a nitrogen atmosphere. Transition temperatures and melting enthalpies were obtained by differential scanning calorimetry (DSC) using a TA Instruments Q20 device at a rate of $10^{\circ} \mathrm{C} \mathrm{min}-1$. Optical absorption spectra were recorded with a UV4-200 UV-Vis spectrophotometer from ATI Unicam. Fluorescence spectra were recorded with a Perkin-Elmer LS50B system. Thin-film spectra were recorded by front-face detection. 


\subsection{Synthetic Methods (See Scheme 1)}

\subsubsection{Synthesis of 3-(4'-Methoxyphenyl)Pentane-2,4-Dione (D1)}

A suspension of 4-iodomethoxybenzene (19.4 mmol, $4.54 \mathrm{~g}), \mathrm{K}_{2} \mathrm{CO}_{3}$ (97.1 mmol, $13.42 \mathrm{~g}), \mathrm{CuI}$ (1.9 mmol, $0.36 \mathrm{~g})$, and (L)-Proline (3.9 mmol, $0.45 \mathrm{~g})$ in DMSO (40 mL) was stirred under argon for $5 \mathrm{~min}$ and then acetylacetone $(58.2 \mathrm{mmol}, 5.82 \mathrm{~g}$ ) was added to the mixture. After three argon-vacuum cycles, the reaction mixture was stirred at $70{ }^{\circ} \mathrm{C}$ for $18 \mathrm{~h}$. Once the reaction had finished, the mixture was poured over an aqueous solution of $\mathrm{HCl} 1 \mathrm{M}(150 \mathrm{~mL})$. After this, the product was extracted with ethyl acetate and washed with water. The organic layer was dried with $\mathrm{MgSO}_{4}$, filtered, then the solution was evaporated. The obtained product was purified by column chromatography (silica gel, hexane/ethyl acetate, 15:1) to give a yellow oil (yield: $1.6 \mathrm{~g}, 41 \% ;{ }^{1} \mathrm{H} \mathrm{NMR}\left(400 \mathrm{MHz}, \mathrm{CDCl}_{3}\right) \delta / \mathrm{ppm}$ (enol tautomer) $16.63(\mathrm{~s}, 1 \mathrm{H}), 7.08-7.06(\mathrm{~m}, 2 \mathrm{H}), 6.92-6.90(\mathrm{~m}, 2 \mathrm{H}), 3.83(\mathrm{~s}, 3 \mathrm{H}), 1.88(\mathrm{~s}, 6 \mathrm{H})$. $\left.{ }^{13} \mathrm{C} \mathrm{NMR}\left(100 \mathrm{MHz}, \mathrm{CDCl}_{3}\right): \delta / p p m ~ 191.2,158.9,132.1,129.1,114.6,114.1,55.2,24.1\right)$.

\subsubsection{Synthesis of 3,5-Dimethyl-4-(4'-Methoxyphenyl)-1H-Pyrazole (P1)}

Hydrazine hydrate $(7.2 \mathrm{mmol}, 0.36 \mathrm{mg}$ ) was added to a mixture of D1 (5.8 mmol, $1.2 \mathrm{~g}$ ) in ethanol $(10 \mathrm{~mL})$ at room temperature. Then, the mixture was heated under reflux for $2 \mathrm{~h}$. The reaction mixture was evaporated under reduced pressure and the residue was purified in ethanol to give a white solid (yield: $1.1 \mathrm{~g}, 91 \% ;{ }^{1} \mathrm{H} \mathrm{NMR}\left(400 \mathrm{MHz}, \mathrm{CDCl}_{3}\right)$

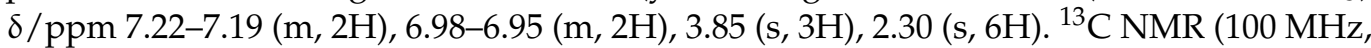
$\mathrm{CDCl}_{3}$ ): $\delta /$ ppm 158.0, 141.7, 130.4, 126.0, 118.0, 113.9, 55.2, 11.5. MS (MALDI+, dithranol) $m / z: 203.1[\mathrm{M}+\mathrm{H}]+$. Analysis found $\mathrm{C}, 70.91 ; \mathrm{H}, 6.94 ; \mathrm{N}, 13.83$. Calc for $\left[\mathrm{C}_{12} \mathrm{H}_{14} \mathrm{~N}_{2} \mathrm{O}\right]$ : C, 71.26; H, 6.98; N, 13.85\%. FTIR v/ $\mathrm{cm}^{-1} 3175$ (N-H), 1613, 1577, 1530, 1247 (C-O-C)).

\subsubsection{Synthesis of 3-(4'-Nitrophenyl)Pentane-2,4-Dione (D2)}

A solution of 4-nitroiodobenzene (11.5 mmol, $2.86 \mathrm{~g}), \mathrm{K}_{2} \mathrm{CO}_{3}(57.2 \mathrm{mmol}, 7.90 \mathrm{~g})$, CuI (1.14 mmol, $0.22 \mathrm{~g}$ ), and (L)-Proline (2.28 mmol, $0.26 \mathrm{~g})$ in DMSO (30 mL) was stirred under argon for $5 \mathrm{~min}$, then acetylacetone $(34.3 \mathrm{mmol}, 3.43 \mathrm{~g})$ was added to the mixture. After three argon-vacuum cycles, the reaction mixture was stirred at $60{ }^{\circ} \mathrm{C}$ for $24 \mathrm{~h}$. Once the reaction had finished, the mixture was poured over an aqueous solution of $\mathrm{HCl} 1 \mathrm{M}$ $(100 \mathrm{~mL})$. After this, the product was extracted with ethyl acetate and washed with water. The organic layer was dried with $\mathrm{MgSO}_{4}$, filtered, and then the solution was evaporated. The obtained product was purified by column chromatography (silica gel, hexane/ethyl acetate, 15:1) to give a yellow oil (yield: $1.9 \mathrm{~g}, 74 \%,{ }^{1} \mathrm{H} \mathrm{NMR}\left(400 \mathrm{MHz}, \mathrm{CDCl}_{3}\right) \delta / \mathrm{ppm}$ (enol tautomer) $16.75(\mathrm{~s}, 1 \mathrm{H}), 8.26-8.24(\mathrm{~m}, 2 \mathrm{H}), 7.40-7.38(\mathrm{~m}, 2 \mathrm{H}), 1.89(\mathrm{~s}, 6 \mathrm{H}) .{ }^{13} \mathrm{C} \mathrm{NMR}$ $\left(100 \mathrm{MHz}_{\mathrm{CDCl}}\right)$ : $\left.\delta / \mathrm{ppm} 190.4,147.3,144.0,132.2,124.0,113.6,24.1\right)$.

\subsubsection{Synthesis of 3,5-Dimethyl-4-(4'-Nitrophenyl)-1H-Pyrazole (P2)}

Hydrazine hydrate $(1.7 \mathrm{mmol}, 0.08 \mathrm{mg}$ ) was added to a mixture of D2 (1.4 mmol, $0.3 \mathrm{~g})$ in ethanol $(10 \mathrm{~mL})$ at room temperature. Then, the mixture was heated under reflux for $2 \mathrm{~h}$. The reaction mixture was evaporated under reduced pressure and the residue was purified by recrystallization in ethanol to give a white solid (yield: $230 \mathrm{mg}, 76 \%$; ${ }^{1} \mathrm{H} \mathrm{NMR}$ $\left(400 \mathrm{MHz} \mathrm{CDCl}_{3}\right) \delta / \mathrm{ppm} 8.29-8.27(\mathrm{~m}, 2 \mathrm{H}), 7.45-7.42(\mathrm{~m}, 2 \mathrm{H}), 2.35(\mathrm{~s}, 6 \mathrm{H}) .{ }^{13} \mathrm{C} \mathrm{NMR}$ $\left(100 \mathrm{MHz}, \mathrm{CDCl}_{3}\right): \delta /$ ppm 141.0, 135.6, 129.5, 123.8, 11.8. MS (MALDI+, dithranol) $\mathrm{m} / \mathrm{z}$ : $218.0[\mathrm{M}+\mathrm{H}]+$. Anal. Found $\mathrm{C}, 60.40 ; \mathrm{H}, 5.00 ; \mathrm{N}, 19.21$. Calc for $\left[\mathrm{C}_{11} \mathrm{H}_{11} \mathrm{~N}_{3} \mathrm{O}_{2}\right]: \mathrm{C}, 60.82$; $\mathrm{H}, 5.10 ; \mathrm{N}, 19.34 \%$. FTIR $\left.v / \mathrm{cm}^{-1} 3174(\mathrm{~N}-\mathrm{H}), 1596,1515\left(\mathrm{NO}_{2}\right), 1342\left(\mathrm{NO}_{2}\right)\right)$.

\subsubsection{Synthesis of 3,5-Dimethyl-4-(4'-Aminophenyl)-1H-Pyrazole (P3)}

Graphite (2.3 g) was added to a solution of D2 $(4.50 \mathrm{mmol}, 1 \mathrm{~g})$ in ethanol $(50 \mathrm{~mL})$ and stirred under an Ar atmosphere. Then, hydrazine hydrate (36.2 mmol, $1.81 \mathrm{~g}$ ) was added. The mixture was stirred under reflux for $12 \mathrm{~h}$. Then, the mixture was filtered over Celite ${ }^{\circledR}$ to remove graphite and washed with hot ethanol. The solvent was evaporated and the product was purified by recrystallization in water to give a white solid (yield: 618 $\mathrm{mg}, 72 \% ;{ }^{1} \mathrm{H} \mathrm{NMR}\left(400 \mathrm{MHz}, \mathrm{CDCl}_{3}\right) \delta / \mathrm{ppm}$ 7.07-7.05 (m, 2H), 6.75-6.73 (m, 2H), 3.78 (s, 
2H), 2.27 (s, 6H). ${ }^{13} \mathrm{C}$ NMR (100 MHz, $\left.\mathrm{CDCl}_{3}\right): \delta / \mathrm{ppm} 144.7,130.2,123.7,118.4,115.2,11.5$. MS (MALDI+, dithranol) $m / z: 188.2[\mathrm{M}+\mathrm{H}]+$. Anal. Found C, 70.63; H, 7.11; N, 22.30. Calc for $\left[\mathrm{C}_{11} \mathrm{H}_{13} \mathrm{~N}_{3}\right]$ : C, 70.56; H, 7.00; N, 22.44\%. FTIR v/cm ${ }^{-1} 3401\left(\mathrm{NH}_{2}\right), 3290\left(\mathrm{NH}_{2}\right)$, 3177 (N-H), 1618, 1585, 1537).

\subsection{Single-Crystal Preparation and Measurement by X-ray Diffraction}

Single crystals of $\mathbf{P 1}$ could only be obtained as a methanol solvate $\mathbf{P 1} \cdot \mathbf{C H}_{3} \mathbf{O H}$. Crystals were grown by vapor diffusion of methanol into a solution of the compound in dichloromethane at room temperature. They were fragile and quickly set up in the instrument at $150 \mathrm{~K}$ to prevent loss of the solvent and degradation. X-ray diffraction data for P1. $\mathrm{CH}_{3} \mathbf{O H}$ were measured at $150 \mathrm{~K}$ on an Xcalibur $\mathrm{S}$ diffractometer from Oxford Diffraction Ltd., using Mo-K $\alpha$ radiation $(\lambda=0.71073 \AA)$. The structure was solved with SIR-92. All hydrogen atoms were placed geometrically except $\mathrm{H} 1 \mathrm{~N}, \mathrm{H} 3 \mathrm{O}, \mathrm{H} 4 \mathrm{~N}$, and $\mathrm{H} 4 \mathrm{O}$, which were localized in electronic density maps and refined with the ShelXL refinement package. Single crystals of P2 and P3 were obtained by vapor diffusion of hexane into a dichloromethane solution at $5{ }^{\circ} \mathrm{C}$ and were stable after filtering and drying at room temperature. Single-crystal X-ray diffraction data for P2 and P3 were acquired at $100 \mathrm{~K}$ using a single-source Agilent SuperNova Atlas diffractometer using $\mathrm{Cu}-\mathrm{K} \alpha$ radiation $(\lambda=1.54184 \AA)$. The structure was solved with the ShelXT structure solution program using intrinsic phasing and refined with the ShelXL refinement package using least squares minimization. A summary of the crystal data and refinement parameters is given in Table 1.

Table 1. Crystal data resolution and refinement parameters.

\begin{tabular}{|c|c|c|c|}
\hline & $\mathrm{P1} \cdot \mathrm{CH}_{3} \mathrm{OH}$ & P2 & P3 \\
\hline Chemical formula & $\mathrm{C}_{13} \mathrm{H}_{18} \mathrm{~N}_{2} \mathrm{O}_{2}$ & $\mathrm{C}_{11} \mathrm{H}_{11} \mathrm{~N}_{3} \mathrm{O}_{2}$ & $\mathrm{C}_{11} \mathrm{H}_{13} \mathrm{~N}_{3}$ \\
\hline Formula mass & 234.29 & 217.23 & 187.24 \\
\hline Crystal system & Triclinic & Monoclinic & Monoclinic \\
\hline$a(\AA)$ & $8.0633(8)$ & $14.5887(2)$ & $21.6136(2)$ \\
\hline$b(\AA)$ & $8.2470(6)$ & $19.8458(2)$ & $11.73111(12)$ \\
\hline$c(\AA)$ & $19.7880(18)$ & $7.24361(12)$ & $16.6400(2)$ \\
\hline$\alpha\left({ }^{\circ}\right)$ & $80.980(7)$ & 90 & 90 \\
\hline$\beta\left(^{\circ}\right)$ & $79.977(8)$ & $97.5482(15)$ & $107.1683(13)$ \\
\hline$\gamma\left({ }^{\circ}\right)$ & $88.969(7)$ & 90 & 90 \\
\hline Unit cell volume $\left(\AA^{3}\right)$ & $1279.7(2)$ & $2079.02(5)$ & $4031.10(8)$ \\
\hline Temperature (K) & $150(1)$ & $99.97(11)$ & $99.98(10)$ \\
\hline Space group & $P^{-}{ }_{\overline{1}}^{\prime}$ & $P 2_{1} / \mathrm{c}$ & $\mathrm{C} 2 / \mathrm{c}$ \\
\hline $\mathrm{N}^{\circ}$ of formula units per unit cell, $\mathrm{Z}$ & 4 & 8 & 16 \\
\hline Radiation type & $\operatorname{MoK} \alpha$ & $\mathrm{CuK} \alpha$ & $\mathrm{CuK} \alpha$ \\
\hline Absorption coefficient, $\mu\left(\mathrm{mm}^{-1}\right)$ & 0.083 & 0.818 & 0.603 \\
\hline $\mathrm{N}^{\circ}$ of reflections measured & 8328 & 15154 & 15405 \\
\hline $\mathrm{N}^{\circ}$ of independent reflections & 4503 & 3876 & 3739 \\
\hline$R_{\text {int }}$ & 0.0337 & 0.0285 & 0.0246 \\
\hline Final $R_{1}$ values $(I>2 \sigma(I))$ & 0.0572 & 0.0332 & 0.0375 \\
\hline Final $\mathrm{w} R\left(F^{2}\right)$ values $(I>2 \sigma(I))$ & 0.1060 & 0.0824 & 0.0993 \\
\hline Final $R_{1}$ values (all data) & 0.0942 & 0.0386 & 0.0415 \\
\hline Final $\mathrm{w} R\left(F^{2}\right)$ values (all data) & 0.1197 & 0.0866 & 0.1029 \\
\hline Goodness of fit on $F^{2}$ & 1.081 & 1.044 & 1.057 \\
\hline
\end{tabular}

\section{Results and Discussion}

\subsection{Synthesis and Characterization}

Pyrazole compounds were obtained following the synthetic route depicted in Scheme 1. The precursory 1,3-diketones were synthesized through a copper-catalyzed arylation reaction of acetylacetone with $p$-iodomethoxybenzene or $p$-iodonitrobenzene [12]; details are given in Materials and Methods. P1 and P2 were obtained by reaction of diketones D1 and D2 with hydrazine hydrate, respectively. P3 was obtained in high yield from the nitrosubstituted acetylacetone D2 in just one step, through a double reduction method using 
graphite and hydrazine hydrate. Pyrazole compounds were characterized by ${ }^{1} \mathrm{H}-\mathrm{NMR}$ and ${ }^{13} \mathrm{C}$-NMR. Elemental analysis confirmed the stoichiometry and purity of the compounds. In addition, mass spectra in the form of the protonated $[\mathrm{M}+\mathrm{H}]^{+}$signal was obtained for all cases.

The IR spectra of the as-obtained solids gave preliminary proof of the existence of supramolecular structures by hydrogen bonding. IR spectra of P1 and P2 showed bands corresponding to the $\mathrm{N}-\mathrm{H}$ stretching of the pyrazole ring in the associated region (3174 or $3175 \mathrm{~cm}^{-1}$ ). The IR spectrum of $\mathbf{P 3}$ showed different N-H bands at 3401, 3290, and $3177 \mathrm{~cm}^{-1}$, indicating a complex arrangement involving $\mathrm{H}$-bonding in both amino and pyrazole N-H groups.

\subsection{Thermal Properties}

The thermal properties of the as-obtained pyrazoles were analyzed by optical microscopy, thermogravimetry (TGA), and differential scanning calorimetry (DSC) (Table 2). P1 does not melt to an isotropic liquid on heating but sublimates at atmospheric pressure. Consistently, the thermogravimetric analysis under an inert atmosphere showed a starting temperature for weight loss of $153{ }^{\circ} \mathrm{C}$, a $5 \%$ weight loss at $196^{\circ} \mathrm{C}$, and quantitative weight loss at $259^{\circ} \mathrm{C}$ in a ramp experiment (Figure 1). P2 and $\mathbf{P} 3$ showed higher thermal stability and melted into isotropic liquids at higher temperatures than P1. As for the TGA experiment for $\mathbf{P} \mathbf{2}$ and $\mathbf{P} 3$, both melted before the weight loss started and showed similar decomposition curves, although $\mathbf{P 2}$ did not decompose without complete volatile emission.

Table 2. Thermal properties.

\begin{tabular}{|c|c|c|}
\hline Compound & 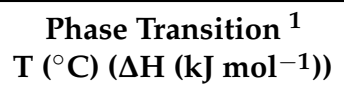 & $\mathrm{T}_{5 \%}\left({ }^{\circ} \mathrm{C}\right)^{2}$ \\
\hline P1 & $\mathrm{Cr} 153^{3} \mathrm{~V}$ & 196 \\
\hline P2 & Cr 193 (24.2) I & 216 \\
\hline P3 & Cr 171 (27.4) I & 214 \\
\hline
\end{tabular}

${ }^{1}$ From DSC thermograms, the first heating cycle at $10{ }^{\circ} \mathrm{C} \mathrm{min}^{-1}$. Cr: crystal; V: vapor; I: isotropic liquid.

2 Temperature of $5 \%$ weight loss, heating rate $10{ }^{\circ} \mathrm{C} \mathrm{min}-1 .{ }^{3}$ Data obtained by optical microscopy using a hot stage.

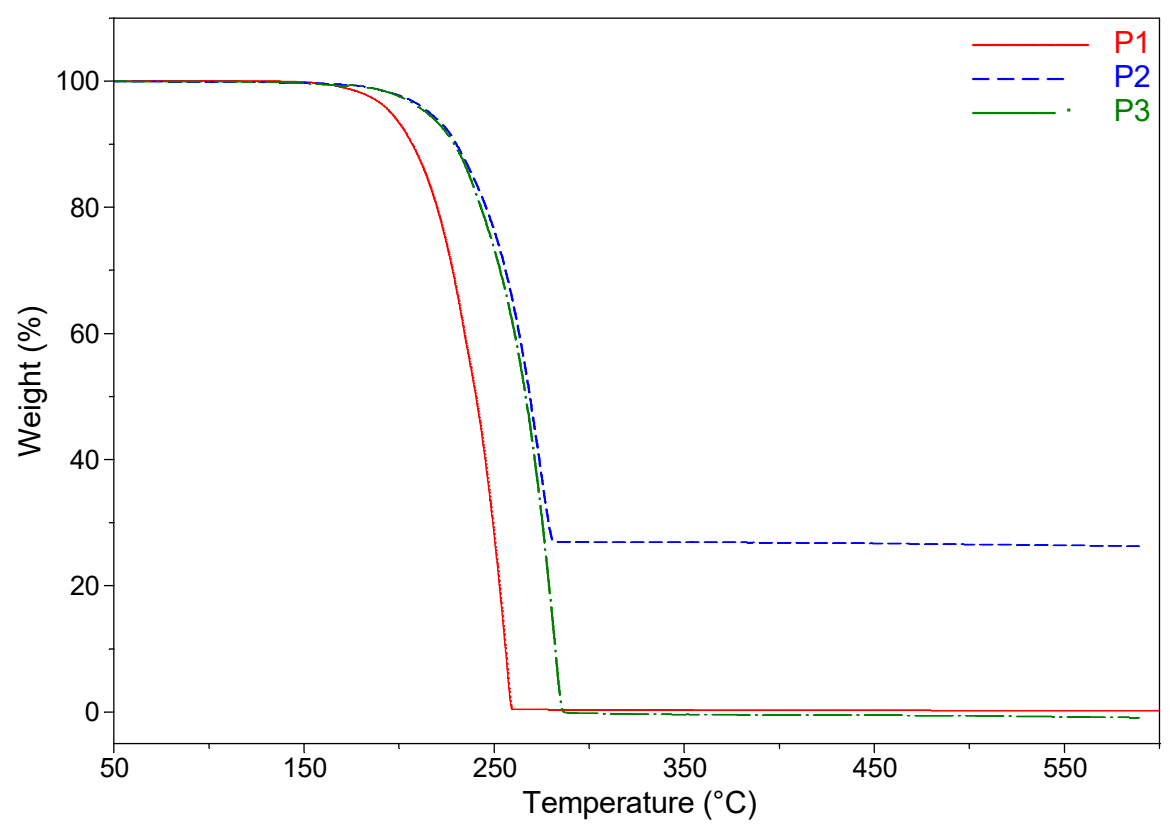

Figure 1. Thermogravimetric analysis curves of the studied pyrazoles. 


\subsection{Optical Properties}

UV-Vis absorption and emission spectra were studied in tetrahydrofuran (THF)diluted solution and in film state (Table 3). P1 and P3 display two absorption bands in the UV region corresponding to $\pi-\pi^{*}$ and $n-\pi^{*}$ transitions. P3 shows a bathochromic shift with respect to P1 corresponding to the electronic effects of the amino group vs. the methoxy group. $\mathbf{P 2}$ displays one absorption band at higher wavelengths corresponding to a charge transfer band due to the effect of the acceptor nitro group and the weak donor effect of the 4-pyrazole group (Figure 2a). P1 and P3 are fluorescent in the near UV region in THF solution and show quite similar emission bands in thin film (Figure 2b). In contrast, P2 does not show fluorescence. This behavior is common for nitroaromatic compounds due to the existence of efficient non-radiative decay processes in solution and the influence of secondary interactions of the nitro group in crystals (see below) [17].

Table 3. UV-Vis absorption and fluorescence data.

\begin{tabular}{|c|c|c|c|c|c|}
\hline Compound & $\begin{array}{c}\lambda_{\mathrm{abs}}(\mathrm{THF}) \\
(\mathrm{nm})\end{array}$ & $\mathcal{E}\left(\mathrm{L} \mathrm{mol}^{-1} \mathrm{~cm}^{-1}\right)$ & $\begin{array}{c}\lambda_{\text {em }}(\mathrm{THF}) \\
(\mathrm{nm})\end{array}$ & $\begin{array}{c}\lambda_{\text {abs }}(\text { Film }) \\
(\mathrm{nm})\end{array}$ & $\begin{array}{c}\lambda_{\text {em }}(\text { Film }) \\
(\mathrm{nm})\end{array}$ \\
\hline P1 & 247,282 & $1.41 \times 10^{4}, 1.96 \times 10^{3}$ & 333 & 250,289 & 328 \\
\hline $\mathbf{P 2}$ & 337 & $1.14 \times 10^{4}$ & - & 333 & - \\
\hline P3 & 260,297 & $1.68 \times 10^{4}, 1.87 \times 10^{3}$ & 355 & 261,295 & 361 \\
\hline
\end{tabular}
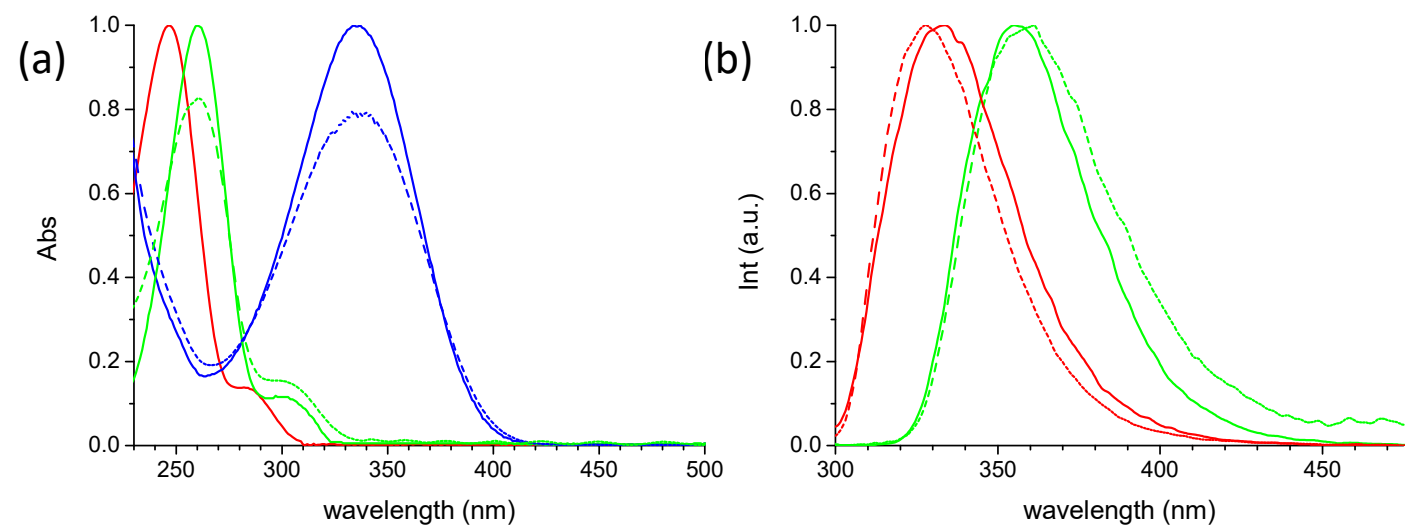

Figure 2. (a) UV-Vis absorption spectra and (b) fluorescence spectra for P1 (red), P2 (blue), and P3 (green). Data relate to samples studied in solution (solid lines) and in film (dashed lines).

\subsection{Single-Crystal Structures and Supramolecular Packing}

In order to study the supramolecular hydrogen-bonded abilities of these $1 \mathrm{H}$-pyrazoles, their single-crystal structures were solved. P1 was obtained as a methanol solvate, while $\mathbf{P} 2$ and $\mathbf{P 3}$ crystallized were obtained as pure compounds.

\subsubsection{Intramolecular Parameters}

Concerning their crystallographic information, $\mathbf{P 1} \cdot \mathbf{C H}_{3} \mathbf{O H}$ crystallized in the triclinic system (space group $\mathrm{P}^{-} \overline{1}$ ) with four molecules of $\mathbf{P} \mathbf{1}$ and four methanol molecules in the unit cell $(Z=4)$. The asymmetric unit is formed by two crystallographically independent molecules and two molecules of methanol. (Figure 3a) P2 crystallized in the monoclinic system (space group $\mathrm{P} 2{ }_{1} / \mathrm{c}$ ) with $\mathrm{Z}=8$ and two crystallographically independent molecules (Figure 3b). $\mathbf{P} 3$ also crystallized in the monoclinic system (space group $\mathrm{C} 2 / \mathrm{c}$ ) with $\mathrm{Z}=16$ and two crystallographically independent molecules (Figure 3c). 

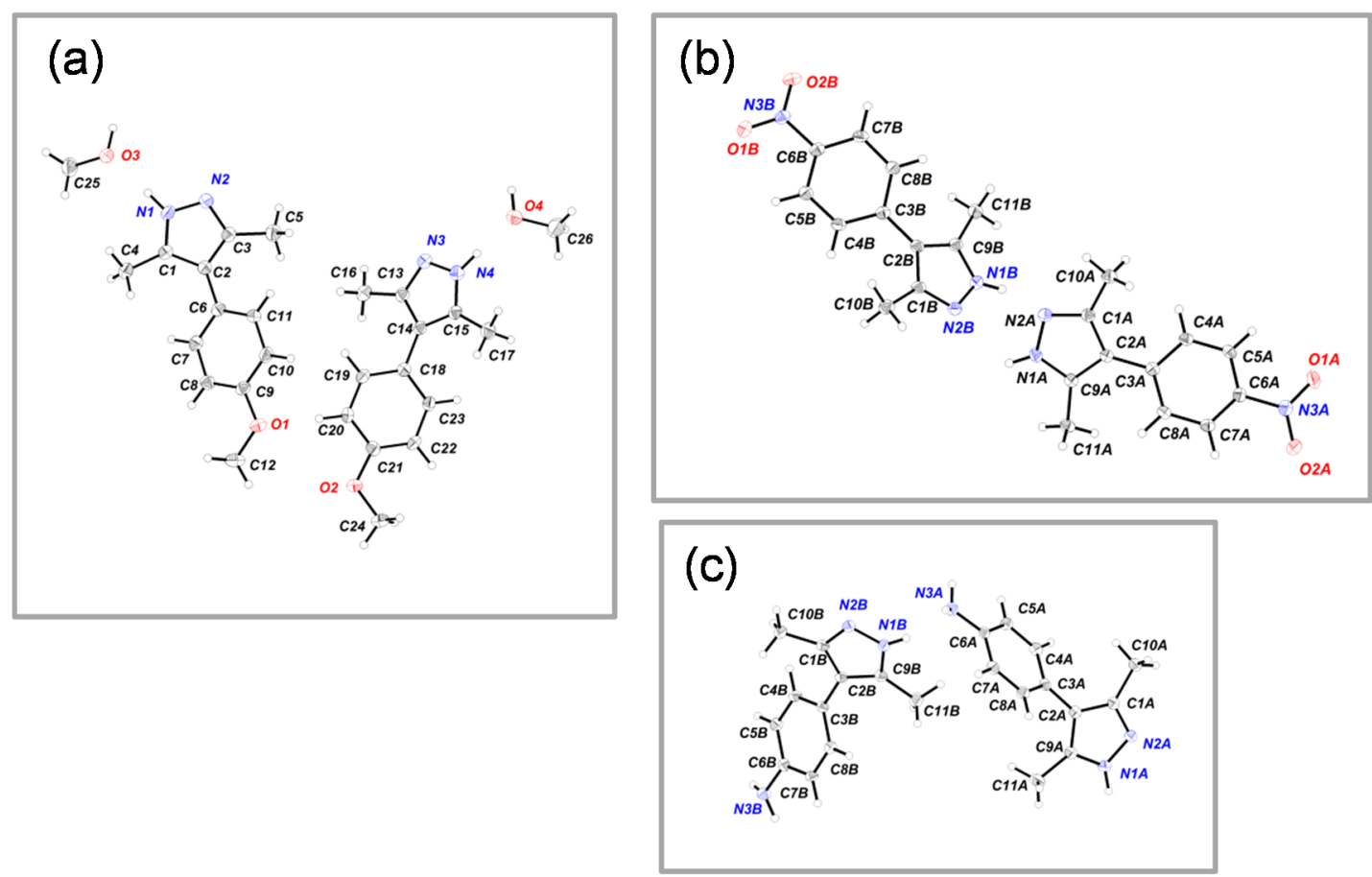

Figure 3. ORTEP diagram (50\% probability of displacement ellipsoids) for various structures: (a) P1·CH $\mathbf{C} \mathbf{O H}$; (b) $\mathbf{P 2}$; (c) $\mathbf{P}$ 3.

At the molecular level, the distances and bond lengths are very similar for the three structures (Table 4) and correspond to the expected values for pyrazole and benzene cycles. Typical measurements for pyrazole rings with alternating distances were found, namely carbon-carbon distances in the pyrazole ring $d\left(p z^{3}-p z^{4}\right)$ larger than $d\left(p z^{4}-p z^{5}\right)$, which correspond to a double-unsaturated ring. Bond distances between pyrazole and benzene rings $\mathrm{d}\left(\mathrm{pz}^{4}-\mathrm{Ph}\right)$ were around 1.46-1.48 $\AA$, indicating low conjugation. Molecules were not planar but were significantly twisted, with pyrazole and benzene forming at angles $\alpha$ of $42^{\circ}$ for $\mathbf{P 1}, 44$ or $46^{\circ}$ for $\mathbf{P 3}$, and 34 or $37^{\circ}$ for P2. Furthermore, P2 was less twisted and the nitro substituent was coplanar with the phenyl ring.

Table 4. Comparison of representative distances $d(\AA)$ and torsion angles between the pyrazole and the phenyl ring $\alpha\left(^{\circ}\right)$.

\begin{tabular}{ccccc}
\hline Compound & $\mathbf{d}\left(\mathbf{p z}^{\mathbf{3}}-\mathbf{p z}^{\mathbf{4}}\right)$ & $\mathbf{d}\left(\mathbf{p z}^{\mathbf{4}}-\mathbf{p z}^{\mathbf{5}}\right)$ & $\mathbf{d}\left(\mathbf{p z} \mathbf{4}^{\mathbf{4}} \mathbf{P h}\right)$ & $\alpha$ \\
\hline $\mathbf{P 1} \cdot \mathbf{C H}_{3} \mathbf{O H}$ & 1.411 & 1.390 & 1.480 & 42.3 \\
& 1.417 & 1.389 & 1.480 & 42.4 \\
$\mathbf{P 2}$ & 1.418 & 1.396 & 1.464 & 36.7 \\
& 1.424 & 1.393 & 1.466 & 34.3 \\
$\mathbf{P 3}$ & 1.419 & 1.387 & 1.475 & 44.2 \\
& 1.417 & 1.392 & 1.477 & 45.7 \\
\hline
\end{tabular}

A search of the literature provided only three more single-crystal structures containing the skeleton of 3,5-dimethyl-4-(4-X-phenyl)- $1 H$-pyrazole $(X=O, N)$. They were the structures with CSD reference codes ZUWLEI $(X=\mathrm{OH})$ [18], OKIKAW (substituted at the 4 position of the pyrazole with a 3,4,5-trimethoxyphenyl group) [13], and REYYIF $(\mathrm{X}=\mathrm{NHCOPh})$ [12]. In addition, one N-substituted pyrazole GIQZAK (3,5-dimethyl-4(2-bromo-4-methoxy-5-hydroxyphenyl)- $N$-phenylpyrazole) was found [19]. For all three $1 H$-pyrazole structures, the phenyl and pyrazole cycles are not coplanar, with angles laying in the same range as found here $\left(44.9^{\circ}, 46.7^{\circ}\right.$, and $45.6^{\circ}$ or $36.0^{\circ}$, respectively). Non-planar structures were also found for other 3,5-dimethyl-4-aryl-1H-pyrazoles, such as NUBZUH $(\mathrm{X}=\mathrm{COOH})$ [20], as well as two bispyrazoles NILREH (aryl = 2-(3,5-dimethylpyrazol-4yl)phenyl) [21] and BOTBUJ (aryl = 3-(3,5-dimethylpyrazol-4-yl)phenyl) [22] and the pyra- 
zolium salts $\mathrm{RABNEN}\left(\mathrm{CF}_{3} \mathrm{COO}^{-}, \mathrm{X}=\mathrm{COOH}\right)$ [23], NUCBAQ $\left(\mathrm{NO}_{3}{ }^{-}, \mathrm{X}=\mathrm{COOH}\right)$ [20], and SUGTIA $\left(\mathrm{Cl}^{-}, \mathrm{X}=\mathrm{PO}_{3} \mathrm{H}_{2}\right)$ [24]. In contrast, a planar geometry was found in the single-crystal structure of 4-phenyl- $1 H$-pyrazole, which provided evidence of the influence of the 3,5-dimethyl substitution [25].

\subsubsection{Intermolecular Hydrogen Bonds and Packing}

Concerning the formation of hydrogen bonds, each independent molecule of P1 interacts with two molecules of methanol through hydrogen bonds. These two molecules of methanol interact with another pyrazole in such a way that two pyrazoles form a dimer through methanol bridges, as shown in Figure 4a. The hydrogen atoms H1N or H4N of the donating pyrazoles interact with the oxygen acceptor of methanol (O3 or $\mathrm{O} 4)$ at distances of $1.863 \AA$ or $1.828 \AA$, respectively. The acceptor nitrogen atoms N2 and N3 interact with the hydrogen atoms of methanol $(\mathrm{H} 3 \mathrm{O}$ and $\mathrm{H} 4 \mathrm{O})$ at distances of $1.79 \AA$ and $1.864 \AA$, respectively. The donor-acceptor distances are around $2.77 \AA$ and the angles deviate slightly from linearity $\left(175^{\circ}\right)$. All data are shown in Table 5 . This supramolecular structure stacks along the $b$ axis (Figure $4 \mathrm{~b}$ ).

Table 5. Intermolecular H-bond data for P1·MeOH.

\begin{tabular}{|c|c|c|c|c|}
\hline D-H $\cdots A$ & D-H (̊̊) & 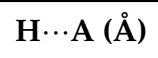 & 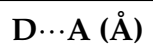 & DH $\cdots A\left(^{\circ}\right)$ \\
\hline N1-H1N $\cdots \mathrm{O} 3$ & 0.91 & 1.863 & 2.769 & 175 \\
\hline N4-H4N ‥O4 & 0.95 & 1.828 & 2.777 & 174 \\
\hline $\mathrm{O} 3-\mathrm{H} 3 \mathrm{O} \cdots \mathrm{N} 2{ }^{1}$ & 0.95 & 1.790 & 2.739 & 176 \\
\hline $\mathrm{O} 4-\mathrm{H} 4 \mathrm{O} \cdots \mathrm{N}^{2}{ }^{2}$ & 0.91 & 1.864 & 2.768 & 176 \\
\hline
\end{tabular}

Note: ${ }^{1}=(x+1,-y+3,-z){ }^{2}=(x+1,-y+2,-z+1)$.

The crystalline packing of $\mathbf{P 2}$ was different to P1. In this case, the pyrazole rings were chained, forming a supramolecular polymer through hydrogen bonds along the $c$ axis (Figure 5a, blue broken lines) involving the two crystallographically independent molecules A and B alternatively. This type of polymeric structure is known as a catemer. Pyrazole rings are twisted at $60.3^{\circ}$ in a zig-zag manner in order to be able to form the chain. The polymers have their nitrophenyl substituents interdigitated with parallel catemers and there are additional hydrogen contacts between these catemers, involving the oxygens of the nitro substituents of one catemer and the methyl groups and $\mathrm{CH}$ of the

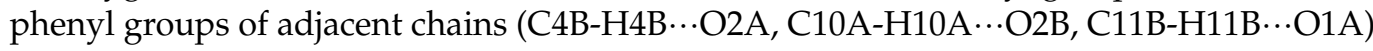
(Table 6) (Figure 5b, red broken lines).

P3 show very different packing to P1 and P2, as a consequence of the H-bonding donating ability of the amino substituent. In this case, the packing consists of a $2 \mathrm{D}$ network of hydrogen bonds in the $a b$ plane. Each molecule is engaged in hydrogen bonds with the other three molecules, giving rise to the formation of supramolecular cycles involving 6 nitrogen atoms, in which two molecules interact through the pyrazole ring and the other two interact through the amino group (Figure 6, Table 7). 
(a)

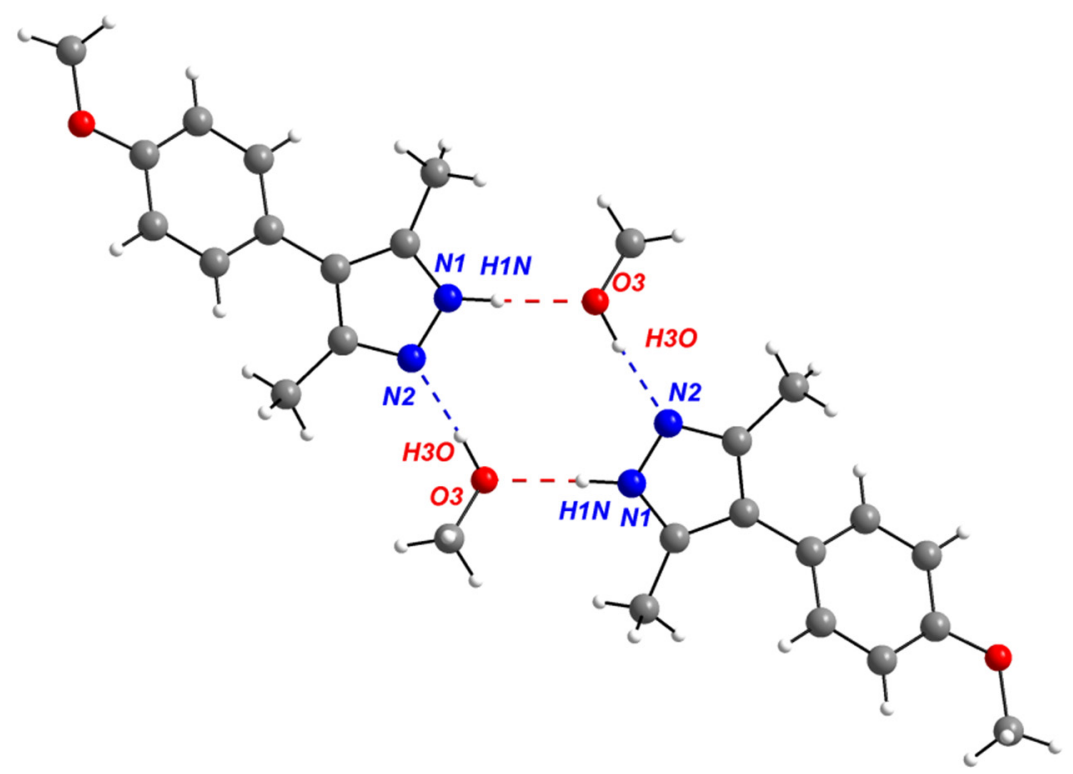

(b)

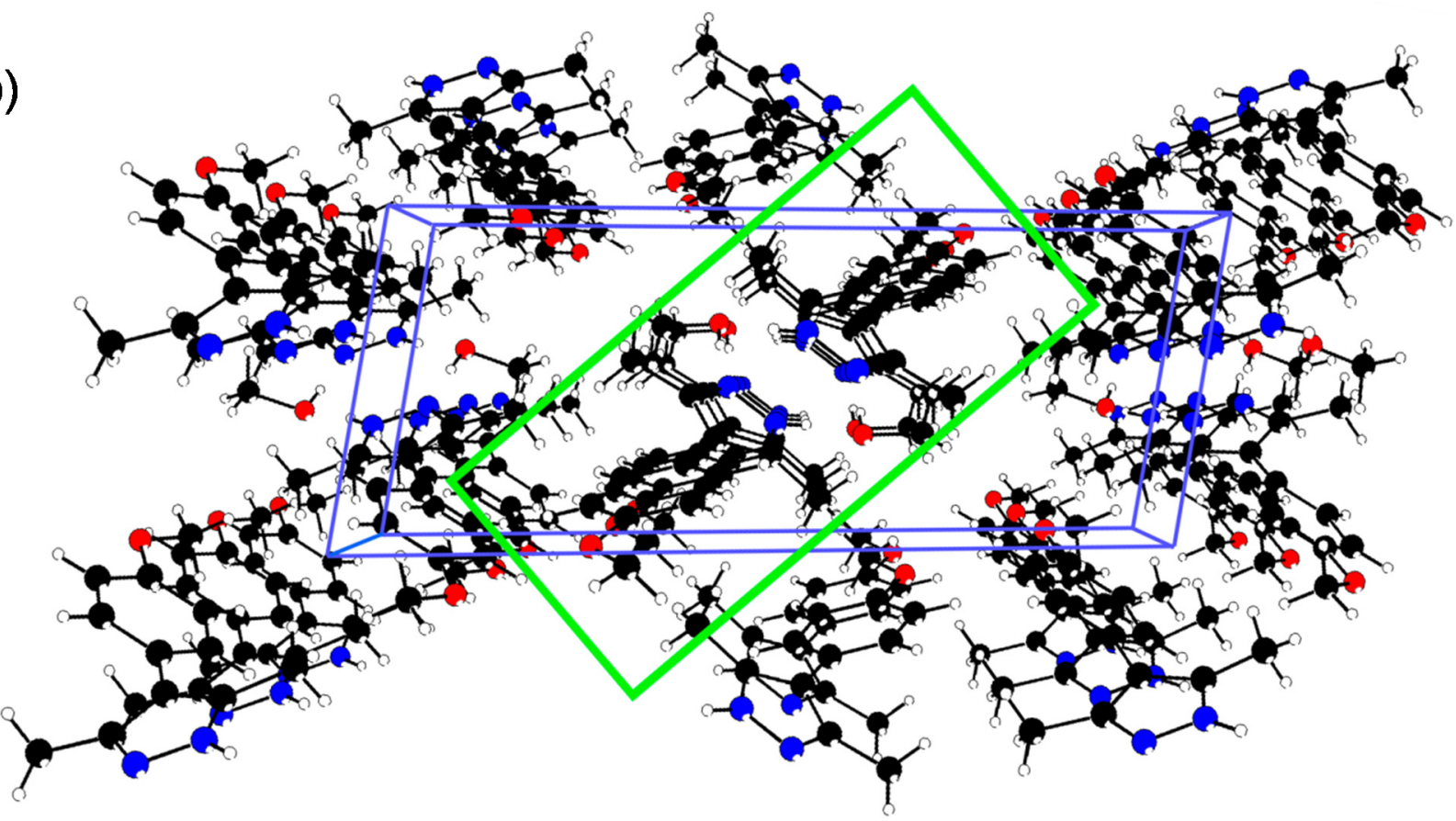

Figure 4. (a) Hydrogen bond formation in $\mathbf{P 1} \cdot \mathrm{CH}_{3} \mathrm{OH}$. (b) Packing of $\mathbf{P 1} \cdot \mathrm{CH}_{3} \mathrm{OH}$ along the $b$ axis. A pile of dimers is highlighted with a green rectangle. 
(a)

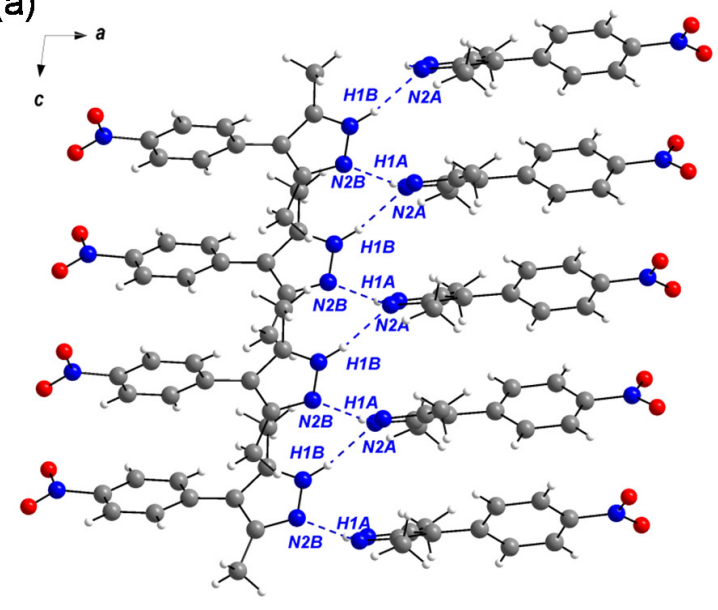

(b)

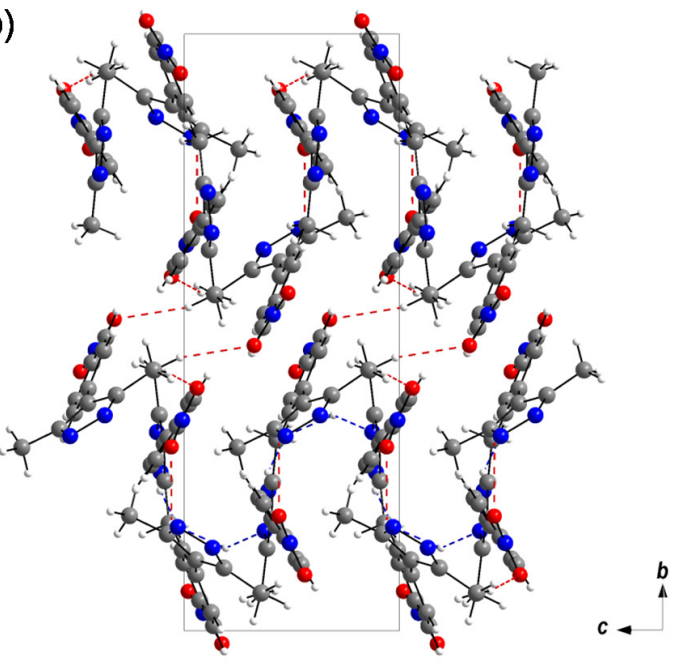

Figure 5. (a) Packing of $\mathbf{P} 2$ in the ac plane, detailing the supramolecular polymer formed by the hydrogen bonds between pyrazole cycles (blue broken lines). (b) View of the $b c$ plane with details of the interactions involving the nitro group (red broken lines).

Table 6. Intermolecular H-bond data and nitro contacts for $\mathbf{P 2}$.

\begin{tabular}{|c|c|c|c|c|}
\hline D-H $\cdots A$ & D-H (Å) & $\mathbf{H} \cdots \mathbf{A}(\AA)$ & $\mathbf{D} \cdots \mathbf{A}(\AA)$ & $\mathrm{D}-\mathrm{H} \cdots \mathrm{A}\left({ }^{\circ}\right)$ \\
\hline N1A-H1A $\cdots$ N2B $^{1}$ & 0.88 & 2.02 & 2.874 & 162 \\
\hline N1B-H1B $\cdots \mathrm{N}^{2} \mathrm{~A}^{2}$ & 0.88 & 2.02 & 2.863 & 160 \\
\hline $\mathrm{C} 4 \mathrm{~B}-\mathrm{H} 4 \mathrm{~B} \cdots \mathrm{O} 2 \mathrm{~A}^{3}$ & 0.95 & 2.57 & 3.458 & 155 \\
\hline C10A-H10A $\cdots \mathrm{O}^{2 B}{ }^{4}$ & 0.98 & 2.54 & 3.488 & 164 \\
\hline C11B-H11B ‥ & 0.98 & 2.51 & 3.485 & 171 \\
\hline
\end{tabular}

Note: ${ }^{1}=(-1+\mathrm{x}, 1 / 2-\mathrm{y},-1 / 2+\mathrm{z}) ;^{2}=(1+\mathrm{x}, \mathrm{y}, \mathrm{z}) ;^{3}=(\mathrm{x}, 1 / 2-\mathrm{y}, 1 / 2+\mathrm{z}){ }^{4}=(-\mathrm{x},-\mathrm{y}, 1-\mathrm{z})$.

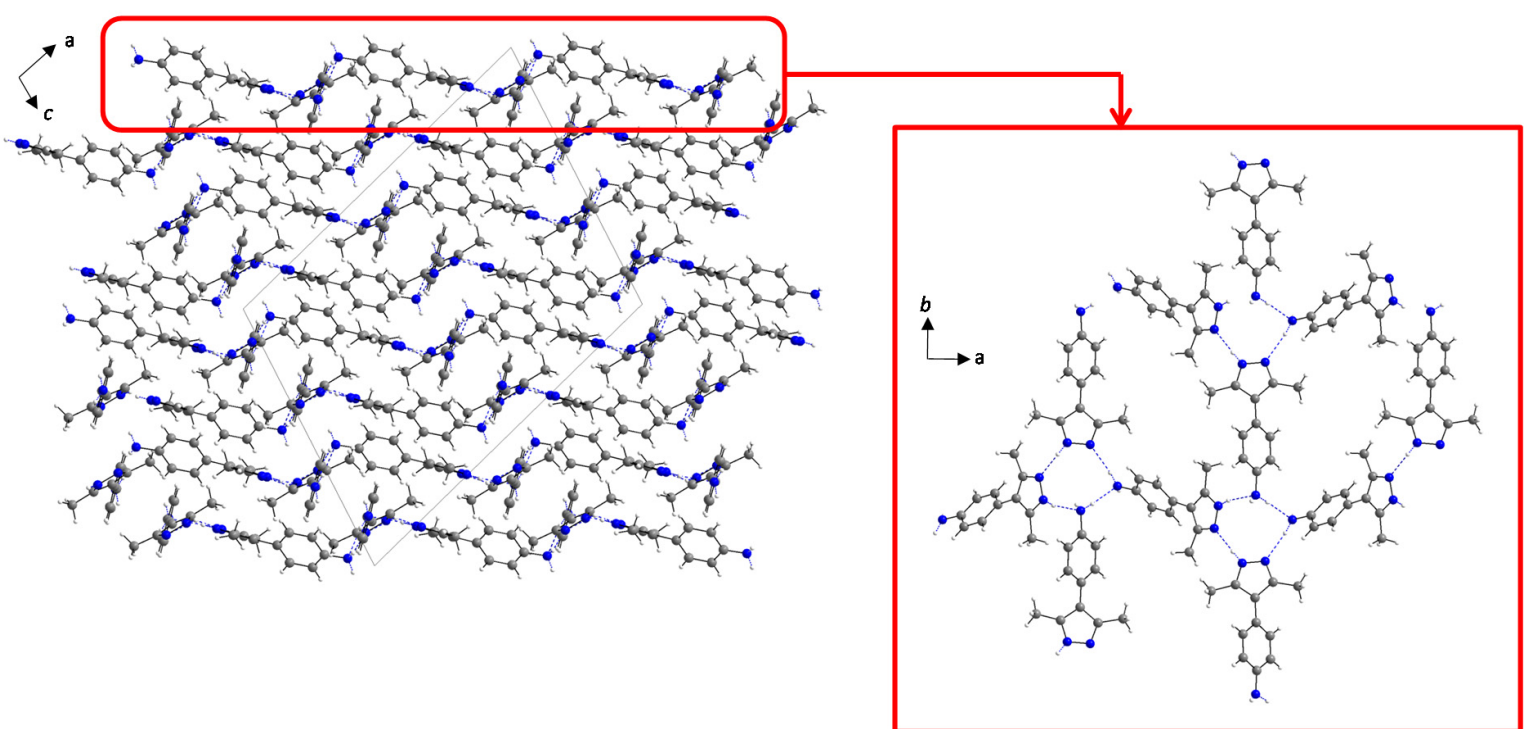

Figure 6. Packing of $\mathbf{P} 3$ in the ac plane and supramolecular 2D network formed by hydrogen bonds between four molecules formed in the $a b$ plane. 
Table 7. Intermolecular H-bond data for P3.

\begin{tabular}{|c|c|c|c|c|}
\hline $\mathrm{D}-\mathrm{H} \cdots \mathrm{A}$ & D-H (Å) & 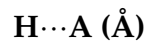 & 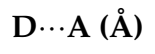 & $\mathrm{D}-\mathrm{H} \cdots \mathrm{A}\left({ }^{\circ}\right)$ \\
\hline N1A-H1A $\cdots$ N2B ${ }^{1}$ & 0.88 & 2.10 & 2.915 & 153 \\
\hline N1B-H1B $\cdots N^{2} A^{2}$ & 0.88 & 2.04 & 2.906 & 166 \\
\hline N3A-H3AB $\cdots$ N3B ${ }^{3}$ & 0.90 & 2.18 & 3.075 & 171 \\
\hline N3B-H3BA $\cdots$ N2A ${ }^{4}$ & 0.90 & 2.16 & 3.047 & 167 \\
\hline
\end{tabular}

Note: ${ }^{1}=(\mathrm{x}, 1-\mathrm{y}, 1 / 2+\mathrm{z}) ;^{2}=(\mathrm{x},-\mathrm{y}, 1 / 2+\mathrm{z}) ;^{3}=(-1 / 2+\mathrm{x},-1 / 2+\mathrm{y}, \mathrm{z}) ;^{4}=(1 / 2+\mathrm{x},-1 / 2+\mathrm{y}, \mathrm{z})$

A comparison of the structures points out that the supramolecular organization is highly dependent on the substitution of the aromatic ring and on the use of methanol in the crystallization process, giving rise to different supramolecular motives, some of which are newly reported here. Methanol solvates are observed when this solvent is used in the crystallization process to bridge two pyrazole molecules via hydrogen bonding. The same result was previously reported for a methanol solvate [12]. Unfortunately, good quality crystals of $\mathbf{P 1}$ could not be grown in the absence of methanol, which prevented the study of its non-solvated form. The catemer structure found for $\mathbf{P 2}$ is unprecedented for neutral 3,5-dimethyl-4-(4-X-phenyl)pyrazoles, as other previously reported substitutions did not give rise to pyrazole-pyrazole interactions, but rather a head-to-tail arrangement of pyrazole-forming chains $[13,19,20]$. In $\mathbf{P 2}$, the pyrazole-pyrazole polymeric chains run parallel and are stabilized by additional secondary interactions involving the nitro group. Finally, a new motif based on supramolecular mixed cycles that form a 2D network was found for the amino substituent compound P3 due to the participation of both amino and pyrazole groups.

\subsubsection{Hirshfeld Surface Analysis}

Hirshfeld surface analysis was performed in order to illustrate the different intermolecular interactions, and in particular hydrogen bonding. Hirshfeld surfaces mapped over the $d_{\text {norm }}$ and 2D fingerprint plots of the three crystal structures (Figure 7) were calculated with the CrystalExplorer 17.5 program [26]. On these surfaces, the short and dominant interactions are displayed as red areas indicating the presence of close contacts such as hydrogen bonds.

(a)
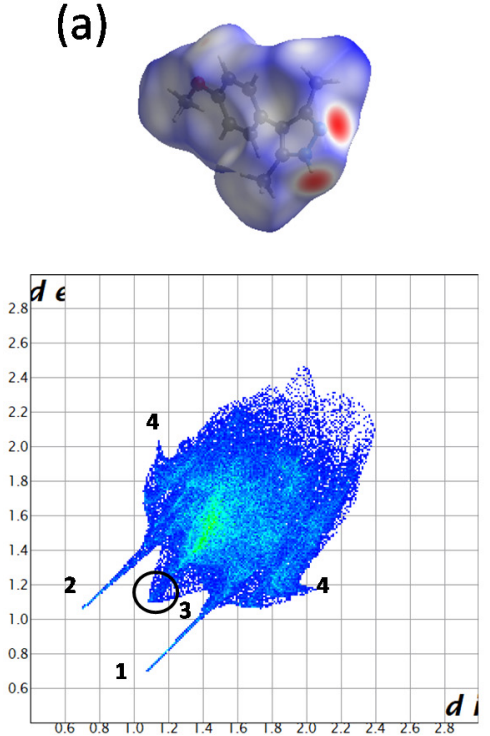

(b)
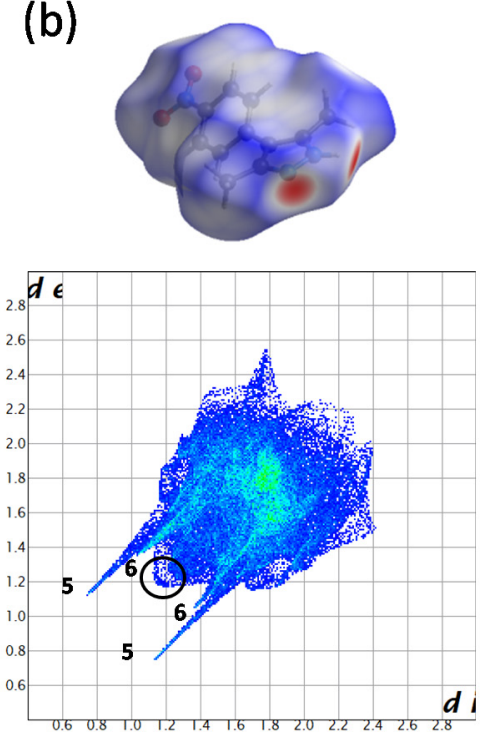

(c)

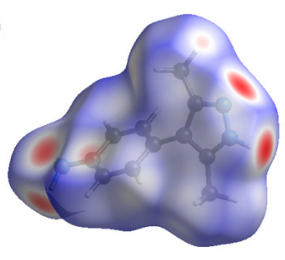

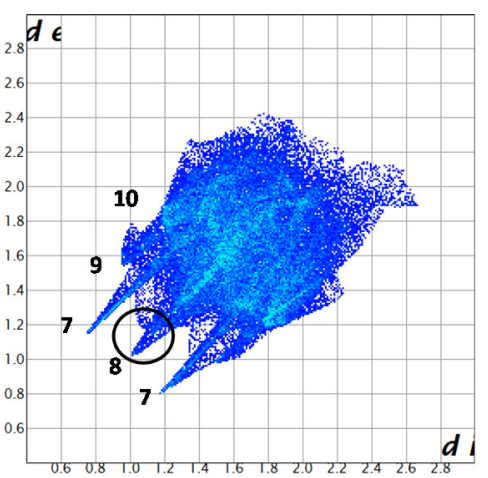

Figure 7. Hirshfeld surfaces mapped over the $d_{\text {norm }}$ and $2 \mathrm{D}$ fingerprint plots for (a) $\mathbf{P} 1 \bullet \mathbf{C H}_{\mathbf{3}} \mathbf{O H},(\mathbf{b}) \mathbf{P} 2$, and (c) $\mathbf{P}$.

The fingerprint plot for $\mathbf{P} 1 \bullet \mathrm{CH}_{3} \mathrm{OH}$ shows two sharp spikes represented by regions 1 and 2 in Figure $7 \mathrm{a}$, which correspond to quite strong hydrogen bond interactions between 
pyrazole and methanol molecules (1: $\mathrm{N} \cdots \mathrm{HO}$ and 2: $\mathrm{NH} \cdots \mathrm{O})$, as reflected in the parameters listed in Table 5, contributing nearly $20 \%$ of the total surface area. In addition, short $\mathrm{O} \cdots \mathrm{H}$ contacts involving the methoxy group (region 3 ) and $\mathrm{C} \cdots \mathrm{H}$ contacts involving methyl groups (region 4) can be seen.

The 2D plot for $\mathbf{P} 2$ shows two clear spikes corresponding to the hydrogen bond interactions between pyrazoles (N-H) (regions labeled as 5 in Figure $7 \mathrm{~b}$ ), representing $15.3 \%$ of the surface area. the important contribution in the crystal stabilization of N-O..H$\mathrm{C}$ interactions $(24.7 \%$ ) (shortest contact region labeled as 6) involving the nitro group can be observed, as listed in Table 6.

For P3, the two regions labeled as 7 (Figure 7c) represent $\mathrm{N} \cdot \mathrm{H}$ hydrogen bonds involving both pyrazole and amino groups, contributing $17.5 \%$ of the total area. The thicker aspects of these spikes compared to previous compounds indicate that more hydrogen bonds are present, although they are at larger di + de, suggesting weaker hydrogen bonds. Area 8 is assigned to short $\mathrm{H} \cdots \mathrm{H}$ contacts between methyl groups of two neighboring pyrazoles (see red spot on the surface of Figure 7c). Areas 9 and 10 indicate the existence of Car-H and N-H, respectively.

It is interesting to note that although the molecular structures and the supramolecular structures are different (dimers, catemers, or 2D networks), the hydrogen bonds contribute to the stabilization of the structure in quite similar proportions $(20 \%, 15.3 \%$, and $17.5 \%$, respectively). In all cases, the $\mathrm{H} \cdots \mathrm{H}$ intermolecular contacts (van der Waals forces), in the middle region of the plot with minimum values marked with a circle make a major contribution to the crystal packing. Similar values can be observed for $\mathbf{P} \mathbf{1} \bullet \mathbf{C H}_{\mathbf{3}} \mathbf{O H}$ and $\mathbf{P 3}$ (60.3\% and 58.3\%, respectively), with lower occurring for P2 (36.1\%) due to the existence of the additional $\mathrm{O} \cdots \mathrm{H}$ interactions.

\section{Conclusions}

The thermal stability, fluorescence, and H-bonding ability of the studied 5-dimethyl-4(4-X-phenyl)-1H-pyrazoles showed clear differences depending on the terminal substituent. From a comparison of the supramolecular structures it was observed that the hydrogen bonds between $1 \mathrm{H}$-pyrazole cycles are greatly influenced by the possibility of forming additional interactions with the chemical group at the para position of the phenyl ring. The nitro substituent, with only hydrogen bond acceptor ability, allows the pyrazole-pyrazole interactions, yielding a catemer or supramolecular polymeric chain. To this structure there is an important contribution of additional short contacts involving the nitro group, which is also reflected in the thermal properties. In contrast, the amino group, which has donor characteristics, interacts with the pyrazole ring and participates in the formation of supramolecular mixed cycles formed by four molecules in the form of an amino-aminopyrazole-pyrazole structure, giving rise to $2 \mathrm{D}$ supramolecular sheets. Hydrogen bonding in the 2D network is weaker than in the dimer or catemer configuration. In addition, the use of protic solvents in the crystallization process as methanol has a fundamental importance as it participates in the formation of hydrogen bonds, bridging two pyrazoles and giving rise to closed "dimers" instead of catemer structures.

Author Contributions: Investigation, S.M., B.D., L.S.F., A.E. and R.G.; writing-original draft preparation, S.M., B.D., L.S.F., A.E. and R.G.; writing-review and editing, R.G.; supervision, A.E. and R.G. All authors have read and agreed to the published version of the manuscript.

Funding: This research was funded by the Gobierno de Aragón (projects PM068/2007, PI109/09, research groups E47_20R and E50_20D), and FEDER/MICIU-AEI/projects PGC2018-093761-B-C31 and CTQ2017-83421-P.

Institutional Review Board Statement: Not applicable.

Informed Consent Statement: Not applicable.

Data Availability Statement: The CCDC numbers 2073139, 2073145, and 2073146 contain the supplementary crystallographic data for the pyrazole compounds studied in this work, $\mathbf{P} \mathbf{\bullet} \bullet \mathrm{CH}_{\mathbf{3}} \mathrm{OH}, \mathbf{P} 2$ 
and P3, respectively. These data can be obtained free of charge from the Cambridge Crystallographic Data Centre via http:/ / www.ccdc.cam.ac.uk/data_request/cif.

Acknowledgments: The authors give thanks for the technical and human support provided by Nuclear Magnetic Resonance, Mass Spectra, and Thermal Analysis Services of CEQMA (CSIC); the X-Ray Diffraction Service of SAI (UZ); and the General X-Ray Service, Molecules and Materials Unit by SGIker (UPV /EHU/ERDF, EU).

Conflicts of Interest: The authors declare no conflict of interest.

\section{References}

1. Hutchins, K.M. Functional materials based on molecules with hydrogen-bonding ability: Applications to drug co-crystals and polymer complexes. R. Soc. Open Sci. 2018, 5, 180564. [CrossRef] [PubMed]

2. Zhang, J.; Zhang, Q.; Vo, T.T.; Parrish, D.A.; Shreeve, J.N.M. Energetic Salts with $\pi$-Stacking and Hydrogen-Bonding Interactions Lead the Way to Future Energetic Materials. J. Am. Chem. Soc. 2015, 137, 1697-1704. [CrossRef] [PubMed]

3. Lin, R.-B.; He, Y.; Li, P.; Wang, H.; Zhou, W.; Chen, B. Multifunctional porous hydrogen-bonded organic framework materials. Chem. Soc. Rev. 2019, 48, 1362-1389. [CrossRef]

4. González-Rodríguez, D.; Schenning, A.P.H.J. Hydrogen-bonded supramolecular $\pi$-functional materials. Chem. Mater. 2011, 23, 310-325. [CrossRef]

5. Kato, T.; Uchida, J.; Ichikawa, T.; Soberats, B. Functional liquid-crystalline polymers and supramolecular liquid crystals. Polym. J. 2018, 50, 149-166. [CrossRef]

6. Desiraju, G.R. Crystal Engineering: From Molecule to Crystal. J. Am. Chem. Soc. 2013, 135, 9952-9967. [CrossRef] [PubMed]

7. Desiraju, G.R. Supramolecular Synthons in Crystal Engineering-A New Organic Synthesis. Angew. Chem. Int. Ed. 1995, 34, 2311-2327. [CrossRef]

8. Halcrow, M.A. Pyrazoles and pyrazolides-flexible synthons in self-assembly. Dalton Trans. 2009, 12, 2059-2073. [CrossRef]

9. Perez, J.; Riera, L. Pyrazole Complexes and Supramolecular Chemistry. Eur. J. Inorg. Chem. 2009, 33, 4913-4925. [CrossRef]

10. Alkorta, I.; Elguero, J.; Foces-Foces, C.; Infantes, L. Classification of hydrogen-bond motives in crystals of NH-pyrazoles: A mixed empirical and theoretical approach. Arkivoc 2006, 2, 15-30. [CrossRef]

11. Foces-Foces, M.C.; Alkorta, I.; Elguero, J. Supramolecular structure of $1 \mathrm{H}$-pyrazoles in the solid state: A crystallographic and ab initio study. Acta Cryst. 2000, 56, 1018-1028. [CrossRef]

12. Moyano, S.; Barberá, J.; Diosdado, B.E.; Serrano, J.L.; Elduque, A.; Giménez, R. Self-assembly of 4-aryl-1H-pyrazoles as a novel platform for luminescent supramolecular columnar liquid crystals. J. Mater. Chem. C 2013, 1, 3119-3128. [CrossRef]

13. Blanco, H.; Iguarbe, V.; Barberá, J.; Serrano, J.L.; Elduque, A.; Giménez, R. Supramolecular Columnar Liquid Crystals with Tapered-Shape Simple Pyrazoles Obtained by Efficient Henry/Michael Reactions. Chem. Eur. J. 2016, 22, 4924-4930. [CrossRef] [PubMed]

14. Moyano, S.; Serrano, J.L.; Elduque, A.; Giménez, R. Self-assembly and luminescence of pyrazole supergelators. Soft Matter 2012, 8, 6799-6806. [CrossRef]

15. Mei, J.; Hong, Y.; Lam, J.W.Y.; Qin, A.; Tang, Y.; Tang, B.Z. Aggregation-Induced Emission: The Whole Is More Brilliant than the Parts. Adv. Mater. 2014, 26, 5429-5479. [CrossRef] [PubMed]

16. Zhao, Z.; Lam, J.W.Y.; Tang, B.Z. Self-assembly of organic luminophores with gelation-enhanced emission characteristics. Soft Matter 2013, 9, 4564-4579. [CrossRef]

17. Sonoda, Y.; Tsuzuki, S.; Goto, M.; Tohnai, N.; Yoshida, M. Fluorescence Spectroscopic Properties of Nitro-Substituted Diphenylpolyenes: Effects of Intramolecular Planarization and Intermolecular Interactions in Crystals. J. Phys. Chem. A 2010, 114, 172-182. [CrossRef]

18. Foces-Foces, C.; Cativiela, C.; Serrano, J.L.; Zurbano, M.M.; Jagerovic, N.; Elguero, J. Molecular structure of 4-p-hydroxyphenyl3,5-dimethylpyrazole monohydrate. J. Chem. Crystallogr. 1996, 26, 127-131. [CrossRef]

19. Taneja, N.; Peddinti, R.K. Metal-free direct C-arylation of 1,3-dicarbonyl compounds and ethyl cyanoacetate: A platform to access diverse arrays of meta-functionalized phenols. Chem. Commun. 2018, 54, 11423-11426. [CrossRef]

20. Bryant, M.R.; Burrows, A.D.; Fitchett, C.M.; Hawes, C.S.; Hunter, S.O.; Keenan, L.L.; Kelly, D.J.; Kruger, P.E.; Mahon, M.F.; Richardson, C. The synthesis and characterisation of coordination and hydrogen-bonded networks based on $4-(3,5-d i m e t h y l-1 \mathrm{H}-$ pyrazol-4-yl)benzoic acid. Dalton Trans. 2015, 44, 9269-9280. [CrossRef]

21. Grzywa, M.; Bredenkötter, B.; Denysenko, D.; Spirkl, S.; Nitek, W.; Volkmer, D. A Metallosupramolecular Octahedron Assembled from Twelve Copper(I) Metal Ions and Six 4,4'-(1,2-Phenylene)bis(3,5-dimethylpyrazol-1-ide) Ligands. Z. Anorg. Allg. Chem. 2013, 639, 1461-1471. [CrossRef]

22. Grzywa, M.; Geßner, C.; Bredenkötter, B.; Denysenko, D.; van Leusen, J.; Kögerler, P.; Klemm, E.; Volkmer, D. Coordination frameworks assembled from $\mathrm{CuII}$ ions and $\mathrm{H}_{2}-1,3-\mathrm{bdpb}$ ligands: X-ray and magneto structural investigations, and catalytic activity in the aerobic oxidation of tetralin. Dalton Trans. 2014, 43, 16846-16856. [CrossRef] [PubMed]

23. Foces-Foces, C.; Cativiela, C.; Zurbano, M.M.; Sobrados, I.; Jagerovic, N.; Elguero, J. Molecular structure of 4-(3,5-dimethylpyrazol1-yl)benzoic acid trifluoroacetate. J. Chem. Crystallogr. 1996, 26, 579-584. [CrossRef] 
24. Nateghi, B.; Janiak, C. Synthesis and characterization of two bifunctional pyrazole-phosphonic acid ligands. Z. Naturforsch. B 2019, 74, 891-899. [CrossRef]

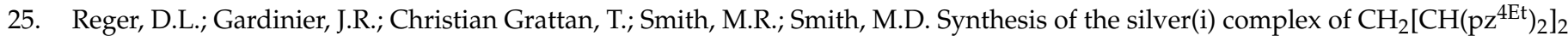
containing the unprecedented $\left[\mathrm{Ag}\left(\mathrm{NO}_{3}\right)_{4}\right]^{3-}$ anion: A general method for the preparation of 4-(alkyl)pyrazoles. New J. Chem. 2003, 27, 1670-1677. [CrossRef]

26. Spackman, P.R.; Turner, M.J.; McKinnon, J.J.; Wolff, S.K.; Grimwood, D.J.; Jayatilaka, D.; Spackman, M.A. CrystalExplorer: A program for Hirshfeld surface analysis, visualization and quantitative analysis of molecular crystals. J. Appl. Crystallogr. 2021, 54, 1006-1011. [CrossRef] 